\title{
Antiarrhythmic and antioxidant activity of novel pyrrolidin-2-one derivatives with adrenolytic properties
}

\author{
Jacek Sapa Alicja Nowaczyk $\cdot$ Katarzyna Kulig
}

Received: 23 April 2010 / Accepted: 20 September 2010/Published online: 15 October 2010

(C) The Author(s) 2010. This article is published with open access at Springerlink.com

\begin{abstract}
A series of novel pyrrolidin-2-one derivatives (17 compounds) with adrenolytic properties was evaluated for antiarrhythmic, electrocardiographic and antioxidant activity. Some of them displayed antiarrhythmic activity in barium chloride-induced arrhythmia and in the rat coronary artery ligation-reperfusion model, and slightly decreased the heart rate, prolonged $\mathrm{P}-\mathrm{Q}, \mathrm{Q}-\mathrm{T}$ intervals and $\mathrm{QRS}$ complex. Among them, compound EP-40 (1-[2-hydroxy3-[4-[(2-hydroxyphenyl)piperazin-1-yl]propyl]pyrrolidin2 -one showed excellent antiarrhythmic activity. This compound had significantly antioxidant effect, too. The present results suggest that the antiarrhythmic effect of compound EP-40 is related to their adrenolytic and antioxidant properties. A biological activity prediction using the PASS software shows that compound EP-35 and EP-40 can be characterized by antiischemic activity; whereas, compound EP-68, EP-70, EP-71 could be good tachycardia agents.
\end{abstract}

\section{J. Sapa $(\square)$}

Department of Pharmacodynamic, Laboratory of Pharmacological

Screening, Faculty of Pharmacy,

Jagiellonian University Medical College,

Medyczna 9,

30-688 Kraków, Poland

e-mail: jaceksapa@interia.pl

\author{
A. Nowaczyk \\ Department of Organic Chemistry, Collegium Medicum \\ in Bydgoszcz, Nicolaus Copernicus University, \\ 9 Skłodowskiej-Curie St, \\ 85-094 Bydgoszcz, Poland \\ K. Kulig \\ Department of Physicochemical Drug Analysis, \\ Chair of Pharmaceutical Chemistry, Faculty of Pharmacy, \\ Jagiellonian University Medical College, \\ Medyczna 9, \\ 30-688 Kraków, Poland
}

Keywords Pyrrolidin-2-one derivatives . $\alpha$-adrenoceptor blocking activity Antiarrhythmic . Occlusion and reperfusion

\section{Introduction}

Now, in the globalization era, determined by speed, uncertainty and instability people live in increasing stress leading to rise of the incidences of cardiovascular diseases. Cardiac arrhythmia is abnormal electrical activity in the heart, may be caused by abnormal impulse formation, abnormal impulse propagation, or both (Matyus et al. 1997). The most frequently diagnosed arrhythmias with major clinical implications included heart chamber fibrillation, i.e. atrial fibrillation (atrial arrhythmias (AF)) and/or ventricular fibrillation (ventricular arrhythmias (VF)) (Nattel and Carlsson 2006). Cardiac arrhythmias remain a major source of morbidity and mortality in developed countries. For example, between 0.5 and 1 million North Americans and Europeans die each year of sudden cardiac death (lead to a high incidence of sudden death in minutes to hours), which causes $10-20 \%$ of all deaths among adults in the Western world (Goldberger et al. 2008; Huikuri et al. 2001; Kromhout 2007). It is also estimated that if present trends continue more than 15 million Americans will be affected by AF by 2050 (Miyasaka et al. 2006). AF is the most common arrhythmia in the population (or the single most common factor in stroke of the elderly) (Rich 2009) whereas VF is the most common cause of sudden cardiac death (Elmas et al. 2008). Antiarrhythmic drugs correct heart beats too quickly (tachycardia), too slowly (bradycardia) or with an irregular pattern (Estrada and Darbar 2008; Golan et al. 2008).

$\alpha_{1}$-Adrenergic receptors $\left(\alpha_{1}\right.$-AR) are members of the Gprotein coupled superfamily of receptors, which modulate 
intercellular biochemical processes in response to changes in extracellular concentration of neurotransmitter norepinephrine and circulating hormone epinephrine, leading to widespread physiological actions that make them attractive target for drug discovery. They are responsible for many functions such as vasconstriction, inotropy, chronotropy, blood pressure regulation, bronchodilation, sedation and analgesia. Suppression of ARs results in vasodilation, decreased heart rate, inotropy and relaxation of prostate smooth muscle (Becker et al. 2004; He et al. 2008; Michelotti et al. 2000; Zhong and Minneman 1999). Thus, $\alpha_{1}$-AR antagonist can be useful in the treatment of hypertension, benign prostatic hyperplasia, lower urinary track symptoms or cardiac arrhythmia (Chiu et al. 2008; Jain et al. 2008; Thiyagarajan 2002).

Our earlier research showed that some pyrrolidin-2-one derivatives had marked significant antiarrhythmic (adrenaline-induced) and hypotensive actives. These compounds had affinity for $\alpha_{1}$ - and $\alpha_{2}$-adrenoceptors and antagonized the pressor response elicited by epinephrine, norepinephrine and methoxamine. The observed effect suggested that these compounds had adrenolytic properties (Kulig et al. 2007; Malawska et al. 2002, 2005). Many studies implicate adrenoceptors in the formation of arrhythmia during myocardial ischemia and reperfusion in the isolated heart. It was shown that $\alpha_{1}$-bloking drugs such as prazosin and phentolamine are also effective against ischemia-induced arrhythmias in a variety of animal models (Bernauer and Ernenputsch 1988; Bralet et al. 1985; Colucci 1982; Lamontagne et al. 1986; Tolg et al. 1997). As a continuation of this study, 17 compounds (high active in adrenaline-induced arrhythmia) were tested in model ventricular arrhythmias associated with coronary artery occlusion and reperfusion in the non-working isolated perfused rat heart (Lubbe and Daries 1978) and additionally in barium chloride-induced arrhythmia in vivo and also for active compounds in reperfusion-induces arrhythmia marked antioxidant activity.

Modern lead discovery and rational drug design cannot nowadays be independent from molecular modeling which can describe the biological activities by using theoretical methods and computational techniques. Up to now, the crystal structures of target of $\alpha_{1}$-ARs and arrhythmic drugs are not known, and for this reason the study of the interactions between the arylpiperazine derivatives and the adrenergic or antiarrhythmic receptor can only be done by methods of molecular modeling. Current drug discovery methods estimate biological response of potential medicinal agents by constructing independent and linear models. Although these models provide a link between specific biological targets and therapeutic effects, the properties of natural signals are too complex to expect that an independent set of descriptors would be capable of forecasting biological responses. Intuitively one can imagine that the molecules having the same scaffold ought to have similar surface and binding affinity (or antiarrhythmic properties) to suitable active site. However if this is truth the $\alpha_{1}$-AR affinity and/or antiarrhythmic activity of investigated set should differ insignificantly, which does not fit to our pharmacological data. The (Q)SAR study was already published (Nowaczyk et al. 2009, 2010). In this work, we describe application of computational of biological activity spectra according to which the compound's biological activity is considered as an intrinsic property of the structure. In this context, the goal of our research was application of computer-aided drug discovery program Predicted Activity Spectrum for Substances (PASS) (PASS 2010; Poroikov and Filimonov 2005).

\section{Materials and methods}

\section{Animals}

The experiments were carried out on male Wistar rats (180 $250 \mathrm{~g}$ ). Animals were housed in constant temperature facilities exposed to $12: 12 \mathrm{~h}$ light/dark cycle and maintained on a standard pellet diet and tap water given ad libitum. All procedures were according to the Animal Care and Use Committee Guidelines, and approved by the Ethical Committee of Jagiellonian University, Kraków. Control and experimental groups consisted of six to eight animals each.

\section{Drugs}

All tested compounds (Scheme 1) were synthesized by the doctor Katarzyna Kulig in the Department of Physicochemical Drug Analysis, Pharmaceutical Faculty, Jagiellonian University. Synthesis of tested compounds was described in previous papers (Kulig et al. 2007).

Barium chloride (POCh, Poland), sodium heparin (Polfa), thiopental sodium (Biochemie Gmbh, Vienna), diphenylhydantoin sodium salt (Epanutin, Parke-Davis), prazosin hydrochloride (Sigma-Aldrich), urapidyl (SigmaAldrich), and quinidine (Sigma-Aldrich).

Ventricular arrhythmias associated with coronary artery occlusion and reperfusion in the non-working isolated perfused rat heart

Hearts from thiopental-anesthetised $(45-60 \mathrm{mg} / \mathrm{kg}$, ip) rats were perfused according to the Langendorff technique (Langendorff 1895) at constant pressure of $70 \mathrm{~cm} \mathrm{H} \mathrm{H}_{2} \mathrm{O}$ $(6.87 \mathrm{kPa})$ with Chenoweth-Koelle solution continuously gassed with $95 \% \mathrm{O}_{2}$ plus $5 \% \mathrm{CO}_{2}$ of the following 


\begin{tabular}{|c|c|c|c|c|c|c|}
\hline Comp & EP-24 & EP-26 & EP-28 & EP-32 & $\begin{array}{c}\text { EP- } \\
35\end{array}$ & $\begin{array}{c}\text { EP- } \\
40\end{array}$ \\
\hline $\mathrm{X}$ & - & - & - & - & - & $-\mathrm{OH}$ \\
\hline & $\mathrm{OCONHCH}\left(\mathrm{CH}_{3}\right)_{2}$ & $\mathrm{OCONHCH}_{2} \mathrm{CH}_{3}$ & $\mathrm{OCONHCH}\left(\mathrm{CH}_{3}\right)_{2}$ & $\mathrm{OCONHCH}\left(\mathrm{CH}_{3}\right)_{2}$ & $\mathrm{OH}$ & \\
\hline $\mathrm{R}$ & $\mathrm{H}$ & $2-\mathrm{OMe}$ & $2-\mathrm{OMe}$ & $2-\mathrm{Cl}$ & $2-\mathrm{F}$ & $\begin{array}{c}2- \\
\mathrm{OH}\end{array}$ \\
\hline $\mathrm{R}_{1}$ & $\mathrm{H}$ & $\mathrm{H}$ & $\mathrm{H}$ & $\mathrm{H}$ & $\mathrm{H}$ & $\mathrm{H}$ \\
\hline Comp. & EP-41 & EP-43 & EP-44 & EP-46 & $\begin{array}{c}\text { EP- } \\
47\end{array}$ & $\begin{array}{c}\text { EP- } \\
67\end{array}$ \\
\hline $\mathrm{X}$ & $\mathrm{H}$ & $-\mathrm{OH}$ & $\mathrm{H}$ & $\mathrm{H}$ & $\mathrm{H}$ & $\mathrm{OH}$ \\
\hline $\mathrm{R}$ & $\mathrm{H}$ & $2-\mathrm{O}-i-\mathrm{Pr}$ & $2-\mathrm{Cl}$ & 2-OEt & $\begin{array}{c}2- \\
\mathrm{Me}\end{array}$ & $\begin{array}{c}2- \\
\mathrm{OMe}\end{array}$ \\
\hline $\mathrm{R}_{1}$ & $\mathrm{H}$ & $\mathrm{H}$ & $\mathrm{H}$ & $\mathrm{H}$ & $\mathrm{H}$ & $\mathrm{Ph}$ \\
\hline Comp. & EP-68 & EP-69 & EP-70 & EP-71 & & \\
\hline$X$ & $\mathrm{OH}$ & $\mathrm{OH}$ & $\mathrm{OH}$ & $\mathrm{OH}$ & & \\
\hline $\mathrm{R}$ & $2-\mathrm{CF}_{3}$ & $\mathrm{OH}$ & 2-OEt & $\mathrm{H}$ & & \\
\hline $\mathrm{R}_{1}$ & $\mathrm{Ph}$ & $\mathrm{Ph}$ & $\mathrm{Ph}$ & $\mathrm{Ph}$ & & \\
\hline
\end{tabular}

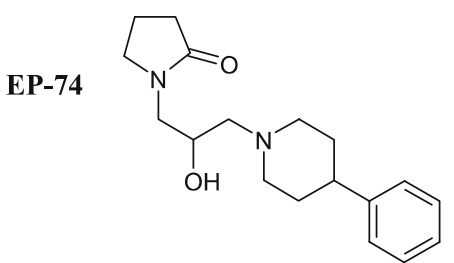

Scheme 1 Schematic structure of new pyrrolidin-2-one derivatives

composition (mmol/l): $\mathrm{NaCl}$ (120.0), $\mathrm{KCl}$ (5.6), $\mathrm{MgCl}_{2}$ (2.2), $\mathrm{NaHCO}_{3}$ (19.0), $\mathrm{CaCl}_{2}$ (2.4) and glucose (10.0).

The effect of tested compounds, in concentration of $10^{-8}$ to $10^{-4} \mathrm{M}$, on coronary flow (cardiac effluent), electrocardiogram (obtained by two stainless steel electrodes, one inserted into the muscle of the ventricular wall and another attached to the metal aortic cannula) were assessed after 15-20 min of initial stabilization.

Non-working isolated hearts were mounted as described above for recording coronary flow and ECG. After a 15 min stabilization period, acute regional myocardial ischaemia was produced for $15 \mathrm{~min}$ by installing a clip on the left coronary artery close to its origin (ischaemic period). The clip was then reopened, and changes during reperfusion were monitored for $30 \mathrm{~min}$ (reperfusion period). Occlusion and reperfusion was verified by measuring coronary flow before occlusion, after occlusion and after reperfusion.

Ligation of the coronary artery resulted in $24-28 \%$ reduction in coronary flow. Reperfusion was followed by a return of the coronary flow. Reperfusion induced arrhythmias, manifested by ventricular premature beats (VBs), ventricular tachycardia (VT) and ventricular fibrillation (VF).
Electrocardiograms (ECGs) were analyzed according to the guidelines of the Lambeth Conventions for VBs, bigeminy, salvos (less than four successive VBs), ventricular tachycardia (VT, four or more successive VBs) and ventricular fibrillation (VF).

In order to obtain a measure for the intensity of the arrhythmias, an Arrhythmia Severity Index was calculated for each heart according to Bernauer (Bernauer and Ernenputsch 1988): the occurrence of up to ten ventricular extrasystoles during the first $30 \mathrm{~min}$ of reperfusion was attributed the value 1 , more than ten the value 2 , ventricular tachycardia or ventricular flutter the value 3 , and ventricular fibrillation the value 4 . Bigeminy and salvos were not quantified separately but included with VBs.

Agents were added to the perfusion medium $15 \mathrm{~min}$ before coronary artery ligation and the concentration was maintained for the rest of the perfusion period.

Prophylactic antiarrhythmic activity in barium chloride-induced arrhythmia acc. to Szekeres (Szekeres and Papp 1975)

Barium chloride solution was injected into the caudal vein of rat $(32 \mathrm{mg} / \mathrm{kg}$, in a volume of $1 \mathrm{ml} / \mathrm{kg})$. The tested compounds 
were given i.v. 15 min before arrhythmogen. The criterion of antiarrhytmic activity was a gradual disappearance of the arrhythmia and restoration of the sinus rhythm.

Antioxidant effect-measurement of lipid peroxidation in rat brain homogenate (Yue et al. 1992)

The rat brain homogenate was made in $0.9 \%$ saline containing $10 \mathrm{mg}$ tissue $/ \mathrm{ml}$. The rates of membrane lipid peroxidation were measured by the formation of thiobarbituric acid reactive substance (TBARS). Rat brain homogenates $(1 \mathrm{ml})$ were incubated at $37^{\circ} \mathrm{C}$ for $5 \mathrm{~min}$ with $10 \mu \mathrm{l}$ of a test compound or vehicle. Lipid peroxidation was initiated by the addition of $50 \mu \mathrm{l}$ of $0.5 \mathrm{mM} \mathrm{FeCl}_{2}$ and $50 \mu \mathrm{l}$ of $2 \mathrm{mM}$ ascorbic acid. After $30 \mathrm{~min}$ of incubation, the reaction was stopped by adding $0.1 \mathrm{ml}$ of $0.2 \%$ BHT. Thiobarbituric acid reagent was then added and the mixture was heated for $15 \mathrm{~min}$ in a boiling water bath. The TBARS was extracted by n-butanol and measured at $532 \mathrm{~nm}$. The amount of TBARS was quantified using a standard curve of MDA as described previously.

\section{Statistical analysis}

The data are expressed as the means \pm SEM or percent. The data were evaluated by one-way analysis of variance followed by Duncan's test or Fisher's test; $p<0.05$ was considered significant.

Computational methods

The computational procedure applied in this study includes:

1. For the molecular 3D structure calculations the Gaussian ${ }^{\circledR} 03$ (version 6.1) package was used (Frisch et al. 2004). The three-dimensional structures of the pyrrolidin-2-one derivatives at their neutral state were obtained through full optimization based on the AM1 quantum chemical procedure. Force field calculations were used to ascertain whether the resulting structures were true energy minima. All the molecules were minimized until the root mean square gradient value became smaller than $10^{-6}$ a.u.

2. Form 3D structure geometry-optimized data generated from Gaussian 03 were create MOL-files use the GaussView 4.1 program (GaussView 2003). Later, MOL-files, were submit individually to the internet version of PASS program and obtain the predicted biological activity spectrum (for prediction activity $(\mathrm{Pa})$ $>$ prediction inactivity $(\mathrm{Pi})$ and $\mathrm{Pa}>0.5$ ).

3. From then full activity spectrum calculated by PASS system our analysis was limited to narrow topic related to cardiovascular diseases such as: Tachycardia, Antiischemic, Antiarrhythmic, Cardiotonic.

\section{Results}

Ventricular arrhythmias associated with coronary artery occlusion and reperfusion in the non-working isolated perfused rat heart

Ligation of the coronary artery resulted in a 35-40\% reduction in coronary flow. Reperfusion was followed by a return of the coronary flow to $80-100 \%$ of the preocclusion values. Reperfusion induced arrhythmias, which manifested by VBs, VT and VF.

During the 30 min period of coronary artery reperfusion, all hearts in the control group developed VBs. The incidence of VT and VF was 60 and $50 \%$, respectively (Tables 1 and 2).

Compared with control hearts, only five compounds (EP-40, EP-44, EP-46, EP-70 and EP-71) significantly diminished the incidence of ventricular tachycardia and ventricular fibrillation (Tables 1 and 2).

The most potent antiarrhythmic effect was produced by compound EP-40, which significantly reduced the incidence of: VBs (50\%), VT (about 20-40\%) and VF (40\%) in concentration $10^{-5}-10^{-4} \mathrm{M}$. The arrhythmias severity index was lower (2.7-3.4), compared with control hearts (5.4).

Compounds: EP-44, EP-46, EP-70 and EP-71 showed weaker antiarrhythmic effect in this model. This compound significantly reduced the incidence of VT and VF in concentration $10^{-5}$ only. In this concentration, their arrhythmias severity index was similar and had a value about 3.0-3.3.

Remaining compounds, used in concentrations of $10^{-6}$ $10^{-4} \mathrm{M}$, did not show antiarrhythmic activity in this test.

Reference drugs in this model : phenytoin and quinidine (I class Vaughan Williams classification), (Vaughan Williams 1975, 1981) showed significantly effect in this test in concentrations $10^{-5}$ (phenytoin) and $10^{-6}-5 \times 10^{-6}$ (quinidine) (Table 2). Alpha adrenolityc drugs: prazosin and urapidyl showed significantly affect only in concentrations $10^{-6} \mathrm{M}$ (Table 2).

Influence of active tested compounds on ECG parameters on the non-working isolated perfused rat heart

The five active tested compounds (EP-40, EP-44, EP-46, EP-70, and EP-71) decreased the number of cardiac beats per minute, prolonged $\mathrm{P}-\mathrm{Q}, \mathrm{Q}-\mathrm{T}$, intervals and $\mathrm{QRS}$ complex. The $\mathrm{QT}_{\mathrm{c}}$ was calculated according to the formulae of Bazzett: $\mathrm{QT}_{\mathrm{c}}=\mathrm{Q}-\mathrm{T} / \sqrt{\mathrm{RR}}$.

All compounds in concentration $10^{-6}-10^{-4} \mathrm{M}$ significantly decreased the number of cardiac beats per minute $\left(10^{-6} \mathrm{M}, 9-16 \% ; 10^{-4} \mathrm{M}, 18-24 \%\right)$. This chronotropic effect was similar to phenytoin $\left(10^{-6} \mathrm{M}, 11 \% ; 10^{-4} \mathrm{M}, 21 \%\right)$ and weaker to quinidine $\left(10^{-7} \mathrm{M}, 10^{-4} \mathrm{M}, 17-35 \%\right)$ (Fig. 1). 
Table 1 Effect of tested compounds on reperfusion-induced arrhythmias

\begin{tabular}{|c|c|c|c|c|c|c|c|}
\hline Compound & $\begin{array}{l}\text { Concentration } \\
\text { (M) }\end{array}$ & $\begin{array}{l}\text { VBs incidence } \\
(\%)\end{array}$ & $\begin{array}{l}\text { Bigeminy } \\
\text { incidence (\%) }\end{array}$ & $\begin{array}{l}\text { Salvos } \\
\text { incidence (\%) }\end{array}$ & $\begin{array}{l}\text { VT incidence } \\
(\%)\end{array}$ & $\begin{array}{l}\text { VF incidence } \\
(\%)\end{array}$ & $\begin{array}{l}\text { Arrhytmias } \\
\text { severity index }\end{array}$ \\
\hline Control & - & 100 & 50 & 30 & 60 & 50 & $5.4 \pm 0.6$ \\
\hline \multirow[t]{3}{*}{ EP-24 } & $10^{-6}$ & 80 & 40 & 20 & 50 & 30 & $4.9 \pm 0.8$ \\
\hline & $10^{-5}$ & 80 & 50 & 20 & 50 & 25 & $4.5 \pm 0.9$ \\
\hline & $10^{-4}$ & 100 & 40 & 30 & 50 & 40 & $4.8 \pm 0.6$ \\
\hline \multirow[t]{3}{*}{ EP-26 } & $10^{-6}$ & 80 & 50 & 40 & 40 & 60 & $5.4 \pm 1.1$ \\
\hline & $10^{-5}$ & 60 & 50 & 30 & 60 & 40 & $4.8 \pm 1.2$ \\
\hline & $10^{-4}$ & 75 & 50 & 25 & 50 & 75 & $5.5 \pm 0.3$ \\
\hline \multirow[t]{3}{*}{ EP-28 } & $10^{-6}$ & 100 & 80 & 20 & 60 & 50 & $5.4 \pm 0.7$ \\
\hline & $10^{-5}$ & 100 & 80 & 40 & 60 & 50 & $5.4 \pm 0.7$ \\
\hline & $10^{-4}$ & 100 & 80 & 40 & 60 & 80 & $6.0 \pm 0.8$ \\
\hline \multirow[t]{3}{*}{ EP-32 } & $10^{-6}$ & 100 & 50 & 40 & 62.5 & 37.5 & $5.0 \pm 0.8$ \\
\hline & $10^{-5}$ & 100 & 25 & 25 & 62.5 & 25 & $4.5 \pm 0.5$ \\
\hline & $10^{-4}$ & 100 & 50 & 25 & 75 & 25 & $5.0 \pm 0.2$ \\
\hline \multirow[t]{3}{*}{ EP-35 } & $10^{-6}$ & 100 & 25 & 12.5 & 75 & 25 & $5.1 \pm 0.2$ \\
\hline & $10^{-5}$ & 87.7 & 12.5 & 12.5 & 62.5 & 25 & $4.5 \pm 0.7$ \\
\hline & $10^{-4}$ & 87.7 & 12.5 & 12.5 & 62.5 & 37.5 & $5.0 \pm 0.3$ \\
\hline \multirow[t]{3}{*}{ EP-40 } & $10^{-6}$ & 60 & 25 & 0 & 40 & 20 & $4.1 \pm 0.7$ \\
\hline & $10^{-5}$ & 50 & 25 & 0 & 20 & 10 & $2.7 \pm 0.4^{* *}$ \\
\hline & $10^{-4}$ & 50 & 50 & 0 & 40 & 10 & $3.4 \pm 0.6^{*}$ \\
\hline \multirow[t]{3}{*}{ EP-41 } & $10^{-6}$ & 87.7 & 12.5 & 12.5 & 62.5 & 25 & $4.5 \pm 0.7$ \\
\hline & $10^{-5}$ & 87.7 & 12.5 & 12.5 & 62.5 & 25 & $4.5 \pm 0.7$ \\
\hline & $10^{-4}$ & 100 & 50 & 25 & 75 & 25 & $5.0 \pm 0.2$ \\
\hline \multirow[t]{3}{*}{ EP-43 } & $10^{-6}$ & 100 & 10 & 10 & 66 & 33 & $5.2 \pm 1.2$ \\
\hline & $10^{-5}$ & 80 & 10 & 0 & 40 & 30 & $3.8 \pm 0.6$ \\
\hline & $10^{-4}$ & 100 & 50 & 25 & 50 & 33 & $4.6 \pm 1.1$ \\
\hline \multirow[t]{3}{*}{ EP-44 } & $10^{-6}$ & 100 & 50 & 17 & 50 & 33 & $4.5 \pm 0.6$ \\
\hline & $10^{-5}$ & 100 & 33 & 17 & 33 & 17 & $3.3 \pm 0.7^{*}$ \\
\hline & $10^{-4}$ & 100 & 50 & 17 & 50 & 17 & $3.8 \pm 0.8$ \\
\hline \multirow[t]{3}{*}{ EP-46 } & $10^{-6}$ & 87.7 & 33 & 33 & 66.4 & 17 & $4.2 \pm 1.1$ \\
\hline & $10^{-5}$ & 87.7 & 17 & 17 & 50 & 0 & $3.2 \pm 0.9^{*}$ \\
\hline & $10^{-4}$ & 100 & 33 & 17 & 50 & 33 & $4.8 \pm 0.6$ \\
\hline \multirow[t]{3}{*}{ EP-47 } & $10^{-6}$ & 100 & 60 & 20 & 40 & 40 & $4.8 \pm 0.7$ \\
\hline & $10^{-5}$ & 100 & 40 & 20 & 20 & 40 & $4.2 \pm 0.9$ \\
\hline & $10^{-4}$ & 100 & 80 & 40 & 20 & 40 & $4.2 \pm 0.9$ \\
\hline
\end{tabular}

Each value was obtained from six to eight hearts

${ }^{*} p<0.05 ; * * p<0.02$ (significantly different to control)

The tested compounds in concentration $10^{-6}-10^{-4} \mathrm{M}$ significantly prolonged $\mathrm{P}-\mathrm{Q}$ intervals $\left(10^{-6} \mathrm{M}, 15-28 \%\right.$; $\left.10^{-4} \mathrm{M}, 38-48 \%\right)$, Q-T intervals $\left(10^{-6} \mathrm{M}, 15-25 \%\right.$; $\left.10^{-4} \mathrm{M}, 28-41 \%\right)$ and QRS complex $\left(10^{-6} \mathrm{M}, 12-21 \%\right.$; $10^{-4} \mathrm{M}, 26-33 \%$ ), (Figs. 2, 3, and 4). The electrocardiographic changes observed after administration of the tested compounds were weaker to those observed for quinidine. Phenytoin similar prolonged $\mathrm{P}-\mathrm{Q}$ and $\mathrm{Q}-\mathrm{T}$ interval, but did not change the QRS complex, (Figs. 1, 2, 3, and 4). The changes of $\mathrm{QT}_{\mathrm{c}}$ were similar to those seen after administration of phenytoine $\left(10^{-5} \mathrm{M}, 11-16 \% ; 10^{-4} \mathrm{M}, 13-\right.$
$18 \%)$. The strongest effect of $\mathrm{QT}_{\mathrm{c}}$ was revealed by quinidine $\left(10^{-6} \mathrm{M}, 19 \% ; 10^{-4} \mathrm{M}, 70 \%\right)$. The obtained results suggest that the new pirrolidin-2-ones derivatives possesses "quinidine-like" properties.

Prophylactic antiarrhythmic activity in barium chloride-induced arrhythmia

For examined rats, intravenous injections of high dose of barium chloride $(32 \mathrm{mg} / \mathrm{kg}$ ) caused a rapid ventricular extrasystoles and ventricular fibrillation at all animals 
Table 2 Effect of tested compounds, phenytoin, quinidine, urapidyl, and prazosin on reperfusion-induced arrhythmias

\begin{tabular}{|c|c|c|c|c|c|c|c|}
\hline Compound & $\begin{array}{l}\text { Concentration } \\
\text { (M) }\end{array}$ & $\begin{array}{l}\text { VBs incidence } \\
(\%)\end{array}$ & $\begin{array}{l}\text { Bigeminy } \\
\text { incidence (\%) }\end{array}$ & $\begin{array}{l}\text { Salvos } \\
\text { incidence (\%) }\end{array}$ & $\begin{array}{l}\text { VT incidence } \\
(\%)\end{array}$ & $\begin{array}{l}\text { VF incidence } \\
(\%)\end{array}$ & $\begin{array}{l}\text { Arrhytmias } \\
\text { severity index }\end{array}$ \\
\hline Control & - & 100 & 50 & 30 & 60 & 50 & $5.4 \pm 0.6$ \\
\hline \multirow[t]{3}{*}{ EP-67 } & $10^{-6}$ & 100 & 25 & 0 & 75 & 50 & $6.0 \pm 0.7$ \\
\hline & $10^{-5}$ & 100 & 25 & 0 & 50 & 25 & $4.5 \pm 0.8$ \\
\hline & $10^{-4}$ & 100 & 50 & 0 & 75 & 25 & $5.2 \pm 0.2$ \\
\hline \multirow[t]{3}{*}{ EP-68 } & $10^{-6}$ & 100 & 75 & 25 & 50 & 50 & $5.5 \pm 1.4$ \\
\hline & $10^{-5}$ & 100 & 50 & 25 & 50 & 50 & $5.5 \pm 1.4$ \\
\hline & $10^{-4}$ & 100 & 50 & 25 & 50 & 25 & $4.5 \pm 0.9$ \\
\hline \multirow[t]{3}{*}{ EP-69 } & $10^{-6}$ & 100 & 50 & 50 & 75 & 25 & $5.2 \pm 0.2$ \\
\hline & $10^{-5}$ & 100 & 0 & 0 & 50 & 25 & $4.5 \pm 0.8$ \\
\hline & $10^{-4}$ & 100 & 0 & 0 & 50 & 25 & $4.5 \pm 0.8$ \\
\hline \multirow[t]{3}{*}{ EP-70 } & $10^{-6}$ & 100 & 17 & 17 & 66.4 & 33 & $5.2 \pm 0.9$ \\
\hline & $10^{-5}$ & 100 & 17 & 0 & 33 & 17 & $3.2 \pm 0.7^{*}$ \\
\hline & $10^{-4}$ & 100 & 50 & 0 & 50 & 33 & $4.5 \pm 1.0$ \\
\hline \multirow[t]{3}{*}{ EP-71 } & $10^{-6}$ & 100 & 50 & 17 & 33 & 33 & $4.0 \pm 0.7$ \\
\hline & $10^{-5}$ & 87.7 & 17 & 0 & 33 & 17 & $3.0 \pm 0.8^{*}$ \\
\hline & $10^{-4}$ & 100 & 50 & 33 & 50 & 17 & $3.8 \pm 0.6$ \\
\hline \multirow[t]{3}{*}{ EP-74 } & $10^{-6}$ & 100 & 75 & 25 & 75 & 50 & $6.2 \pm 0.9$ \\
\hline & $10^{-5}$ & 100 & 75 & 0 & 75 & 25 & $5.2 \pm 0.2$ \\
\hline & $10^{-4}$ & 100 & 50 & 0 & 50 & 50 & $5.5 \pm 0.3$ \\
\hline \multirow[t]{3}{*}{ Phenytoin } & $10^{-6}$ & 100 & 0 & 0 & 75 & 0 & $4.3 \pm 0.3$ \\
\hline & $10^{-5}$ & 100 & 0 & 0 & 25 & 0 & $2.6 \pm 0.4 * *$ \\
\hline & $10^{-4}$ & 100 & 25 & 0 & 40 & 20 & $4.1 \pm 0.7$ \\
\hline \multirow[t]{2}{*}{ Quinidine } & $10^{-6}$ & 83.3 & 16.7 & 0 & 50 & 0 & $2.3 \pm 0.76^{*}$ \\
\hline & $5 \times 10^{-6}$ & 16.7 & 0 & 0 & 33.3 & 0 & $1.2 \pm 0.6^{* * *}$ \\
\hline \multirow[t]{2}{*}{ Urapidyl } & $10^{-6}$ & 90 & 25 & 0 & 25 & 12.5 & $3.6 \pm 0.2^{*}$ \\
\hline & $10^{-5}$ & 100 & 50 & 0 & 50 & 40 & $4.9 \pm 0.3$ \\
\hline \multirow[t]{2}{*}{ Prazosin } & $10^{-6}$ & 60 & 0 & 0 & 23.5 & 10 & $2.8 \pm 0.6^{* *}$ \\
\hline & $10^{-5}$ & 90 & 0 & 0 & 50 & 30 & $4.0 \pm 0.6$ \\
\hline
\end{tabular}

Each value was obtained from six to eight hearts

$* p<0.05 ; * * p<0.02 ; * * * p<0.001$ (significantly different to control)

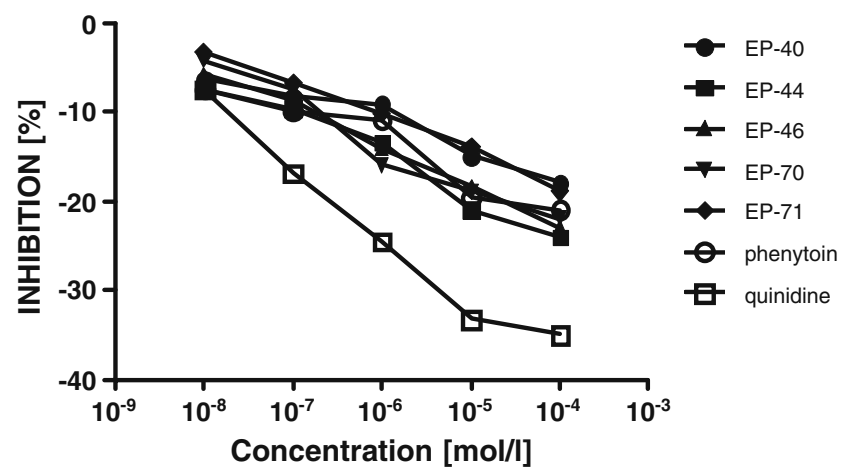

Fig. 1 Influence of active tested compounds on heart rate
(100\%), which led to the death within 3-8 min. The tested compounds were given intravenously $15 \mathrm{~min}$ before arrhythmogen (Figs. 5 and 6).

The highest activity was demonstrated by compound EP40 , which reduced incidence of ventricular fibrillation (by $50 \%$ ) and decreased number of extrasystoles (by 33\%) in doses 10 and $20 \mathrm{mg} / \mathrm{kg}$. In these doses, it protected the animals against death, too (by 50\%). Compounds EP-46 and EP-70 inhibited occurrence of ventricular fibrillation in $50 \%$, but only in dose $20 \mathrm{mg} / \mathrm{kg}$. This compounds decreased number of extrasystoles in $25 \%$. Compound EP-70 reduced mortality of tested animals in $50 \%$. Compounds EP-24, EP-26, EP-32, EP-35, EP-41, EP-43, EP-44, EP-47, EP-67, EP-68, EP-69, EP-71, and EP-74 possessed weak antiarrhythmic properties, reduced incidence of ventricular fibrillation in $10-40 \%$ (Table 3 ). 


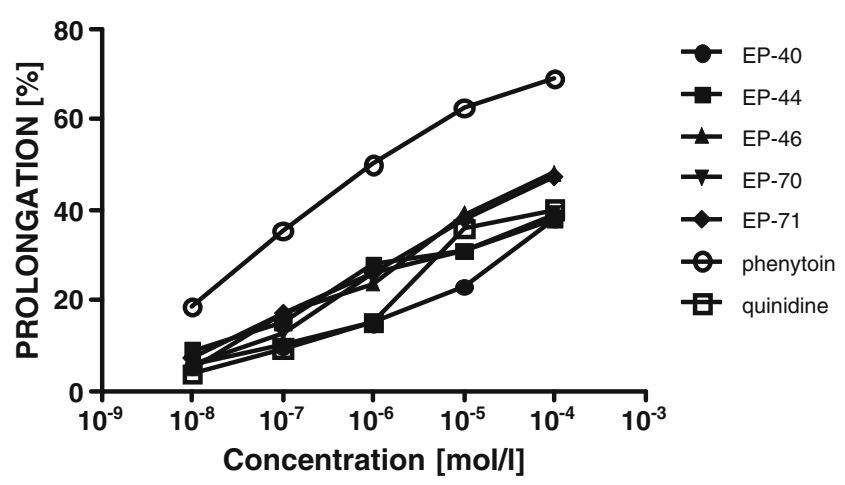

Fig. 2 Influence of active tested compounds on $\mathrm{P}-\mathrm{Q}$ intervals

Quinidine (in dose $15 \mathrm{mg} / \mathrm{kg}$ ) inhibited occurrence of ventricular fibrillation in $34 \%$ and reduced mortality of tested animals in $64 \%$ and phenytoin (in dose $10 \mathrm{mg} / \mathrm{kg}$ ) inhibited occurrence of ventricular fibrillation in $31 \%$ and reduced mortality of tested animals in 56\% (Table 3 ).

Urapidyl and prazosin ( $\alpha$-blocking agents) administered $15 \mathrm{~min}$ before barium chloride, did not change the occurrence of disturbances, but it slightly reduced the number of premature ventricular beats.

Antioxidant effect-measurement of lipid peroxidation in rat brain homogenate

The antioxidant effect was studied for five compounds, active in model reperfusion-induced arrhythmias: EP-40, EP-44, EP-46, EP-70, and EP-71. In this experiment, only compound EP-40 significantly inhibited $\mathrm{Fe}^{2+}$-initiated lipid peroxidation, measured as TBARS, in rat brain homogenate.

\section{Molecular modeling results}

The biological activities of the 17 analogues of 1-(3-(4arylpiperazin-1-yl)-propyl)-pyrrolidin-2-ones were predicted individually by the software PASS. Furthermore, a literature survey revealed two new arylpiperazine arrhyth-

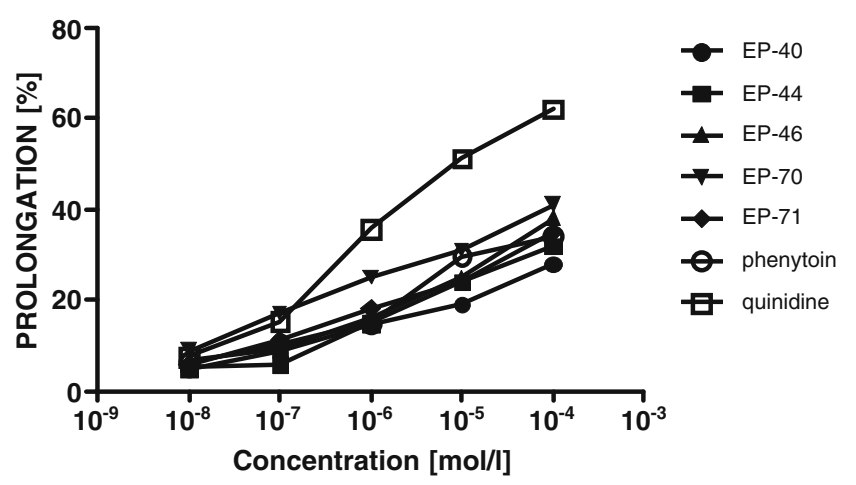

Fig. 4 Influence of active tested compounds on Q-T intervals

mic drugs: the RSD992 (Hayes et al. 2002) and RS87337 (Dumez et al. 1989). These arylpiperazine compounds (structurally like our molecule) exhibited significant protection against isochemic arrhythmias in rat models. These agents were found to possess an electrophysiologic profile characteristic of both classes I and III (mixed sodium/ potassium channels blocking properties). RSD922 exhibited characteristics of an isochaemia-selective and frequency-dependent sodium channel blocker and fully protected rats from isochaemia-included arrhythmias (Hayes et al. 2002). The RS87337 exhibit unusual combination of classes III and I activity may be effective against re-entry phenomena such as occur in atrial fluter. Administration of RS87337 significantly reduced the incidence of fibrillation and death (Dumez et al. 1989). All of these actions suggest that compounds like RSD992 and RS87337 could be effective in treatment of several types of arrhythmia. In this context structure of the RSD992 and RS87337 were chosen for predicted the biological activity by PASS as a reference for class I and III. All computations were performed by computer system PASS server (http://www.ibmh.msk.su/PASS). Traditional QSAR and 3D molecular modeling methods are successful at predicting the biological activities for chemical structures, for small number of types of activity. In reality many biologically active compounds possess several types of

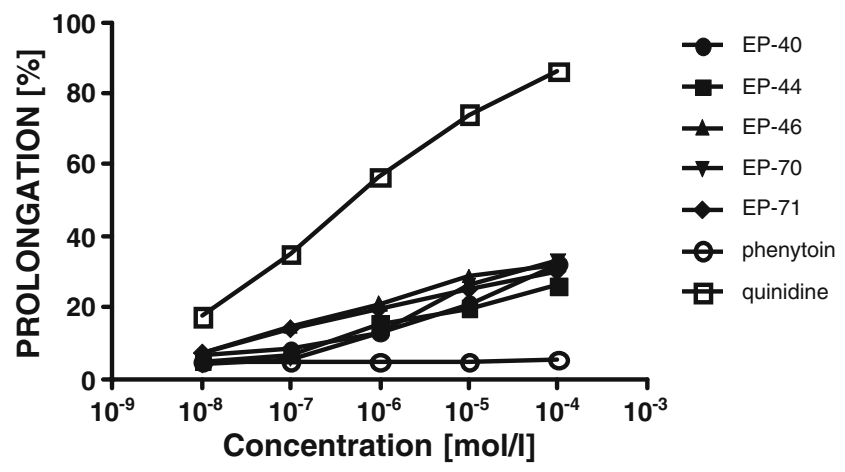

Fig. 3 Influence of active tested compounds on QRS complex

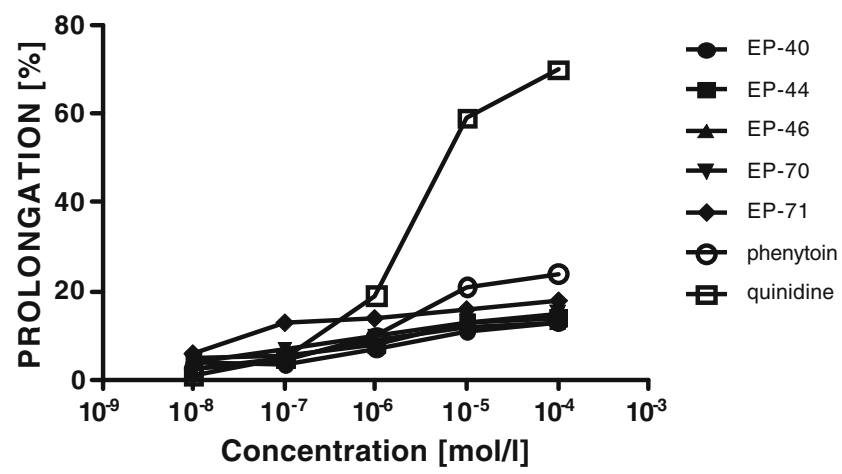

Fig. 5 Influence of active tested compounds on $\mathrm{Q}-\mathrm{T}_{\mathrm{c}}$ intervals 


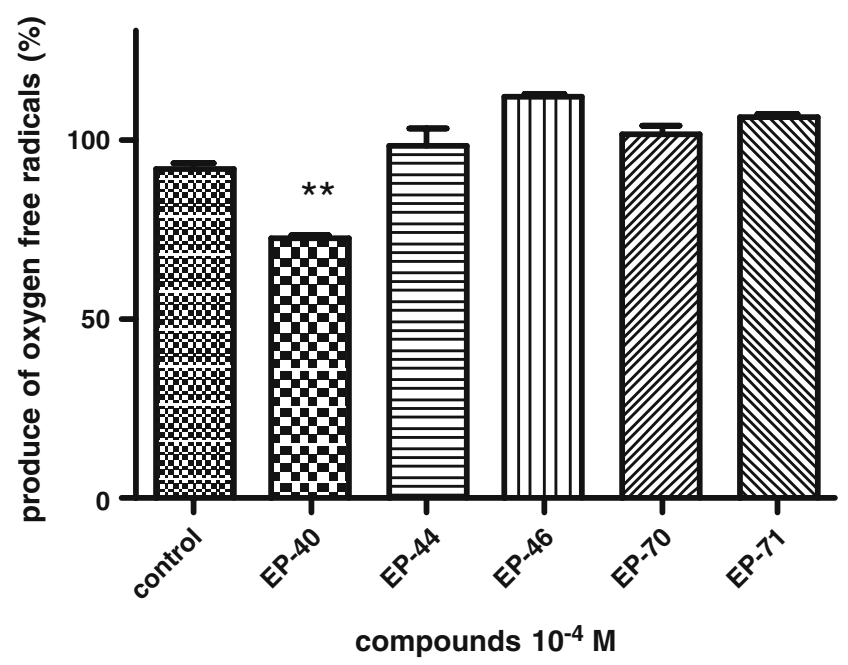

Fig. 6 Antioxidant effect of tested compounds

activity. The PASS system is able to predict many types of activity for a substance (predicts simultaneously several hundreds of various biological activities). The current version of PASS predicts simultaneously 3,678 biological activity types for 46,000 compounds including pharmacotherapeutic effects, mechanisms of action, interaction with drug-metabolizing enzymes, side effects, and toxicity. PASS system gives only qualitative information of certain compound activity in specific activity. The results consist only of $\mathrm{Pa}$ or $\mathrm{Pi}$, which are the estimates of probability for the compound to be active and/or inactive in each type of activity from the biological activity spectrum. Computed values vary within the range of $0.0-1.0$. Activities with $\mathrm{Pa}$ $>\mathrm{Pi}$ are considered as possible for a particular compound. In the case of $\mathrm{Pa}>0.7$, the expectation of activity and the chance of being the analogue of the known pharmaceutical agents for this compound are high. By the contrary, $\mathrm{Pa}<0.7$ indicates that compound is not so similar to the known pharmaceutical agents and its activity must be considered less probable. Detailed description of these software can be found on the web-site (PASS) and its applications can be found in the literature (Fleisher et al. 2009; Gholivand et al. 2009; Marwaha et al. 2007; Poroikov and Filimonov 2005; Poroikov et al. 2000). In this work, we have limited the prediction with following parameters: $\mathrm{Pa}>\mathrm{Pi}$ and $\mathrm{Pa}>0.5$. In Table 4, we have limited the number of presented activities to these of the cardiac relationship of the whole activity spectra set. According to the results, the prediction of the activity as tachycardia by compound EP-68, EP-70, EP-71 and antiischemic by compounds: EP-35, EP-40 and RS87337 are high $(\mathrm{Pa} \geq 0.7)$. Remarkably high probable $(\mathrm{Pa} \geq 0.9)$ of the mechanisms of antiarrhythmic action poses compounds EP-41, EP-43, EP-44, EP-46. Similarly high probability $(\mathrm{Pa} \geq 90)$ was found for mechanisms of cardiotonic action in compounds EP-43, EP-47, EP-67.

\section{Discussion}

The existence of $\alpha_{1}$-AR in the human heart has been proven using molecular biology, biochemical methods and functional studies (Brodde et al. 2006; Salvi 2001). Even though it is well recognized that $\beta$-adrenergic receptor $(\beta$ AR) stimulation markedly increases the contractility of human myocardium, the role of myocardial $\alpha$-adrenergic receptors $(\alpha-\mathrm{AR})$ in mediating the positive inotropic effect of catecholamines in humans is not known (Landzberg et al. 1991). It was found that this subtype of the receptors is quite rare in the human heart and as yet it is not well characterized (Brodde et al. 2006). Cardiomyocytes of all mammalian species express all subtype of $\alpha_{1}$-AR, even if their numbers represent only $25 \%$ to those of $\beta$ adrenoreceptors. However, in the failing human heart, there is a down regulation of $\beta$-AR while the number of $\alpha$-AR is unchanged. Cardiomyocytes exposed to acute ischemia for as short as $10 \mathrm{~min}$ have been shown to exhibit a two- to threefold increase in the numbers of $\alpha_{1}$-adrenoreceptors (Salvi 2001). Therefore, the more $\beta$-AR are reduced in serve heart failure, the more important $\alpha$-AR mediated positively inotropic effect might become to maintain cardiac contractility (Bohm et al. 1988). The $\alpha$-AR are present in both normal and failing human left ventricular myocardium and mediate a positive inotropic effect in several other species; it is not known whether stimulation of myocardial $\alpha$-AR exerts a positive inotropic effect or contributes to basal contractile state in vivo in humans. $\alpha_{1}$-AR receptors play an important role in cardiac growth in the children and in the adult heart they inhibit the generation of atrial and ventricular arrhythmias. Stimulation (in vivo, in humans) of myocardial $\alpha_{1}$-AR receptors increases contractility (Landzberg et al. 1991). The myocardial $\alpha_{1}$-adrenergic receptors are functionally active in humans may also have implications for other actions of the myocardial $\alpha_{1}$-adrenergic receptor.

It is known that most pyrrolidin-2-one derivatives displayed affinity for $\alpha_{1}$ - and $\alpha_{2}$-adrenoceptors and strong antiarrhythmic and hypotensive activity (Kulig et al. 2007). Based on these data, now the antiarrhythmic activity of novel pyrrolidin-2-one derivatives with adrenolytic properties was examined in arrhythmia associated with coronary artery occlusion and reperfusion in the non-working isolated perfused rat heart and in barium chloride-induced arrhythmia.

Many authors suggest that the rat coronary artery ligation and reperfusion model can be recommended as a screen for new antiarrhythmic agents (Starmer et al. 1991; Brooks et al. 1989; Curtis et al. 1987; Uematsu et al. 1986; Walker et al. 1988). Re-opening of the occluded left coronary artery led to arrhythmias which began almost immediately after the coronary flow was restored. The 
Table 3 Prophylactic antiarrhytmic activity in barium chloride-induced arrhythmia

\begin{tabular}{|c|c|c|c|c|}
\hline Compound & Dose $(\mathrm{mg} / \mathrm{kg})$ & Extrasystoles reduce $(\%)$ & Ventricular fibrillation reduce $(\%)$ & Mortality reduce $(\%)$ \\
\hline EP-24 & 20 & 20 & 20 & 20 \\
\hline EP-26 & & 40 & 40 & $50 *$ \\
\hline EP-28 & & 20 & 0 & 20 \\
\hline EP-32 & & 0 & 20 & 20 \\
\hline EP-35 & & 0 & 20 & 20 \\
\hline \multirow[t]{3}{*}{ EP-40 } & 20 & 33 & $50^{*}$ & $50^{*}$ \\
\hline & 10 & 33 & $50^{*}$ & $50 *$ \\
\hline & 5 & 17 & 0 & 17 \\
\hline \multirow[t]{3}{*}{ EP-41 } & 20 & 17 & 0 & 17 \\
\hline & 10 & 40 & 17 & $50^{*}$ \\
\hline & 5 & 17 & 0 & 17 \\
\hline \multirow[t]{3}{*}{ EP-43 } & 20 & 20 & 25 & 20 \\
\hline & 10 & 10 & 0 & 10 \\
\hline & 5 & 0 & 0 & 0 \\
\hline \multirow[t]{3}{*}{ EP-44 } & 20 & 0 & 17 & $50^{*}$ \\
\hline & 10 & 33 & 33 & 33 \\
\hline & 5 & 33 & 17 & $50^{*}$ \\
\hline \multirow[t]{2}{*}{ EP-46 } & 20 & 25 & $50^{*}$ & 25 \\
\hline & 10 & 10 & 20 & 20 \\
\hline \multirow[t]{3}{*}{ EP-47 } & 20 & 20 & 20 & 20 \\
\hline & 10 & 0 & 20 & 20 \\
\hline & 5 & 0 & 20 & 0 \\
\hline EP-67 & 20 & 0 & 10 & 20 \\
\hline EP-68 & & 17 & 17 & 0 \\
\hline EP-69 & & 20 & 20 & 10 \\
\hline \multirow[t]{2}{*}{ EP-70 } & 20 & 25 & $50^{*}$ & $50^{*}$ \\
\hline & 10 & 20 & 25 & $50^{*}$ \\
\hline \multirow[t]{2}{*}{ EP-71 } & 20 & 25 & 25 & 25 \\
\hline & 10 & 0 & 25 & 25 \\
\hline EP-74 & 20 & 17 & 17 & 33 \\
\hline Quinidine & 15 & 34 & 34 & $64^{*}$ \\
\hline Phenytoin & 10 & 27 & 31 & $56^{*}$ \\
\hline
\end{tabular}

$*_{p}<0.05$ (significantly different to control)

importance role in the genesis of ventricular arrhythmias associated with coronary artery occlusion and reperfusion plays the products of hypoxic metabolism and reperfusion of ischemic myocardium. These products include locally released catecholamines, potassium, thromboxane and oxygen-derived free radicals (Bernier et al. 1989; Bralet et al. 1985; Curtis et al. 1987; Page et al. 2002; Rohilla et al. 2010) concluded that inhibitors of the fast inward current (class I agents) and inhibitors of the inward current (class IV agents) appear to be particularly effective antiarrhythmics in rats against both ischemia- and reperfusion-induced arrhythmias.

The five tested compounds (EP-40, EP-44, EP-46, EP-70, and EP-71) exhibited antiarrhythmic effects, in arrhythmia associated with coronary artery occlusion and reperfusion rat models but the strogest effect was revealed by compound EP40, (Tables 1 and 2). The antiarrhythmic activity of compound EP-40 in this test was comparable to that reported for phenytoin, urapidyl and prazosin. Binding studies presented in the previous papers (Kulig et al. 2007; Malawska et al. 2002, 2005) showed that compound EP-40 had affinity for $\alpha_{1}$ - and $\alpha_{2}$-adrenoceptors $\left(\alpha_{1}-K_{i}=194 \mathrm{nM}\right.$; $\left.\alpha_{2}-K_{i}=2260 \mathrm{nM}\right)$ and antagonized the pressor response elicited by epinephrine, norepinephrine and methoxamine. The observed effect suggested that these compounds had adrenolytic properties, preferential to $\alpha_{1}$-adrenoceptors.

It has been well known that $\alpha$-blocking agents (phentolamine, prazosin, corynanthine, rauwolscine and yohimbine) in relatively high doses diminished or prevented reperfusion arrhytmias and cardiac arrhythmias caused by 
Table 4 The probabilities of being active $\mathrm{Pa}$ of the test compounds on the basis of PASS prediction
$P a$ predictive activity values, $P i$ predictive inactivity values

${ }^{\text {a }}$ Predictive biological activities

${ }^{\mathrm{b}}$ Predictive mechanisms

of action

[N-(3,5-dichlorophenyl)-4(4-hydroxy-2-methoxyphenyl)1-piperazinecarboxamidine

\begin{tabular}{|c|c|c|c|c|c|c|c|c|}
\hline \multirow[t]{2}{*}{ Compounds } & \multicolumn{2}{|c|}{ Tachycardia $^{a}$} & \multicolumn{2}{|c|}{ Antiischemic $^{\mathrm{a}}$} & \multicolumn{2}{|c|}{ Cardiotonic $^{\mathrm{b}}$} & \multicolumn{2}{|c|}{ Antiarrhytmic $^{\mathrm{b}}$} \\
\hline & $\mathrm{Pa}$ & Pi & $\mathrm{Pa}$ & $\mathrm{Pi}$ & $\mathrm{Pa}$ & $\mathrm{Pi}$ & $\mathrm{Pa}$ & $\mathrm{Pi}$ \\
\hline EP-24 & & & 0.664 & 0.020 & & & & \\
\hline EP-26 & & & 0.604 & 0.033 & 0.532 & 0.005 & & \\
\hline EP-28 & & & 0.631 & 0.027 & 0.595 & 0.005 & & \\
\hline EP-32 & & & 0.663 & 0.020 & 0.502 & 0.005 & & \\
\hline EP-35 & 0.603 & 0.0662 & 0.704 & 0.015 & 0.909 & 0.004 & 0.780 & 0.004 \\
\hline EP-40 & 0.528 & 0.107 & 0.737 & 0.012 & 0.892 & 0.004 & 0.614 & 0.005 \\
\hline EP-41 & 0.609 & 0.059 & 0.589 & 0.038 & 0.985 & 0.004 & 0.928 & 0.004 \\
\hline EP-43 & & & 0.634 & 0.026 & 0.980 & 0.004 & 0.911 & 0.004 \\
\hline EP-44 & 0.546 & 0.096 & 0.599 & 0.035 & 0.987 & 0.003 & 0.934 & 0.003 \\
\hline EP-46 & 0.618 & 0.054 & 0.565 & 0.046 & 0.982 & 0.003 & 0.923 & 0.004 \\
\hline EP-47 & 0.537 & 0.102 & 0.546 & 0.052 & 0.960 & 0.004 & 0.874 & 0.004 \\
\hline EP-67 & 0.588 & 0.070 & 0.565 & 0.046 & 0.938 & 0.004 & 0.836 & 0.004 \\
\hline EP-68 & 0.757 & 0.019 & 0.633 & 0.026 & & & & \\
\hline EP-69 & 0.633 & 0.047 & 0.572 & 0.043 & & & 0.600 & 0.006 \\
\hline EP-70 & 0.725 & 0.023 & 0.580 & 0.041 & 0.709 & 0.004 & 0.709 & 0.004 \\
\hline EP-71 & 0.713 & 0.025 & 0.601 & 0.034 & & & 0.575 & 0.008 \\
\hline EP-74 & 0.670 & 0.035 & 0.612 & 0.031 & & & 0.705 & 0.004 \\
\hline RDS992 & 0.566 & 0.084 & 0.590 & 0.038 & & & & \\
\hline RS87337 & & & 0.697 & 0.016 & & & & \\
\hline
\end{tabular}

adrenaline intoxication (Bernauer and Ernenputsch 1988; Bralet et al. 1985; Colucci 1982; Lamontagne et al. 1986; Tolg et al. 1997). Phentolamine, a non-selective blocker of $\alpha_{1}$ - and $\alpha_{2}$-adrenoceptors, and the selective $\alpha_{1}$-adrenoceptor antagonist prazosin could reduce the incidence of ischemia-induced ventricular fibrillation, which is in accordance with several studies in the ischemic or reperfused rat, cat and dog myocardium (Corr et al. 1978, 1981, 1986; Corr and Witkowski 1984; Stewart et al. 1980; Sheridan et al. 1980; Sharma et al. 1983; Thandroyen et al. 1983; Benfey et al. 1984; Heusch 1990).

Out of five tested derivatives, only EP-40 had significantly antioxidant effect. Oxygen free radicals have been implicated in myocadial damage during ischemic insults, and especially during the initiation of reperfusion (Yue et al. 1992). Oxygen free radicals play the importance role in the genesis of ventricular arrhythmias associated with coronary artery occlusion and reperfusion (Bernier et al. 1989; Bralet et al. 1985). The importance of oxygen radicals in ischemic myocardial damage is further supported by the protective effect of antioxidans such as U74500A, a 21-aminosteroid (lazaroid), (Yue et al. 1992).

Only compound EP-40 administered $15 \mathrm{~min}$ before barium chloride in dose of $10 \mathrm{mg} / \mathrm{kg}$ it prevented in a statistically significant manner the occurrence of ventricular fibrillation in $50 \%$. This effect was higher than the antiarrhythmic effect of phenytoin and quinidine in the barium chloride model of arrhythmia. Barium ions decrease the outward potassium currents across blocking the ultrarapid delayed rectifier $\mathrm{K}^{+}$channels and inwardly rectifying $\mathrm{K}^{+}$channels (Kir), pacemaker $\mathrm{K}^{+}$channels $\left(\mathrm{I}_{\mathrm{K}}\right)$, background $\mathrm{K}^{+}$channels $\left(\mathrm{I}_{\mathrm{K} 1}\right)$, Ach-induced $\mathrm{K}^{+}$current $\left(\mathrm{I}_{\mathrm{K}, \mathrm{ACh}}\right)$, calcium-activated $\mathrm{K}^{+}$channels $\left(\mathrm{I}_{\mathrm{Ca}}\right)$ and ATP-sensitive $\mathrm{K}^{+}$ channels $\left(\mathrm{I}_{\mathrm{K}, \mathrm{ATP}}\right)$, fatty acids-activated $\mathrm{K}^{+}$channels $\left(\mathrm{I}_{\mathrm{AA}}\right)$, (Boyett et al. 1996; Carmeliet 1999). Blocking of potassium channels by barium ions cause rapid diastolic depolarization and initiation of spontaneous repetitive activity by mechanisms of early afterdepolarizations and spontaneous phase 4 depolarization (abnormal automaticity) (Ino et al. 1995). As a consequence of its $\mathrm{K}^{+}$chanel-blocking action, barium prolongs $\mathrm{Q}-\mathrm{T}$ interval. It known that, antiarrhythmic drugs (lidocaine, phenytoin), which blocking $\mathrm{Na}^{+}$ channel, reduce the $\mathrm{Na}^{+}$current and abolish early and delayed afterdepolarization (EADs and DADs). It is of interest to note that $\alpha$-antagonists (phentolamine, prazosin, and yohimbine) blocked the fast sodium channels in manner similar to that displayed by lignocaine or quinidine (Northover 1983).

Additionally, in our earlier research EP-40 showed the weak local-anesthetic activity - which is possible by blocking the fast sodium channels.

Preliminary pharmacological experiment in vitro showed that compound EP-40 (similarly: EP-44, EP-46, EP-70 and EP-71) slightly decreased the heart rate, and prolonged the P-Q, Q-T intervals and QRS complex. The changes in ECG were similar but a lot weaker comparing to the 
quinidine. Additionally these compounds did not prolong significantly the calculated interval $\mathrm{QT}_{\mathrm{c}}$ (Bazzett formulae) as opposed to the quinidine. This is very essential because compounds which prolong significantly calculated interval $\mathrm{QT}_{\mathrm{c}}$ can have proarrhythmic proprieties (Clerck et al. 2002; Crumb and Cavero 1999). Due to the pharmacological data presented above suggest that the antiarrhythmic effect of compound EP-40 (1-[2-hydroxy-3-[4-[(2-hydroxyphenyl) piperazin-1-yl]propyl]pyrrolidin-2-one may be related to their $\alpha$-adrenolytic and antioxidant properties.

The principle of structure-activity relationships (SAR) theory is assumption that similar molecule suppose to have similar activities. Consequently the SAR study is focused on discovery which parts of the molecule are important to biological activity and which are not. Additionally, information about significant structure features (essential groups of a molecule) open opportunity for generating more knowledge (explanation and understanding) about particular biological responses. According to PASS predictions, shown in Table 4, EP-70 and EP-71 should have tachycardic activity. This indicates that compounds EP-70 and EP-71 may occur to be a close analogue of known pharmaceutical tachycardic agents. Furthermore, in both cases this activity was found experimentally and is accompained by significantly diminished incidence of vascular tachycardia and ventricular fibrillation. Compounds EP-35, EP-40 according to PASS prediction is probably highly similar structurally to known antiischemic agents and supposes to have antiischemic activity. But the antiarrhytmic activity in the ischemia-reperfusion model was found in EP-40 only. These two systems differ in structure by the substituent at position 2 at aryl ring (for EP-35 it is F and for EP-40 OH group).

Rational drug discovery methods estimate biological response of potential medicinal agents by steric effects and variety of specific and nonspecific intermolecular interactions such as: hydrogen bonding, ionic interactions, hydrophobic interactions, Van der Waals interactions or some combinations of them. Considering the differences in the structure of compounds EP-35 and EP-40 one should thoroughly focused on chemical properties of the aryl part. The type of substituent on phenyl ring markedly influences the properties of the compound including the biological activities. While EP-35 and EP-40 differ only in the substituent at position 2 of the phenyl ring ( $\mathrm{F}$ and $\mathrm{OH}$, respectively) it is important to discus few general features of these moiety. It is well known that unsubstituted benzene (sometimes abbreviated $\mathrm{Ph}-\mathrm{H}$ ) is perfectly planar. The electrostatic potential surface obtained from quantum mechanical calculations shows the build-up of negative electrostatic potential in the center of the carbon ring surrounded by positive electrostatic potential localized on hydrogen atoms. $\mathrm{Ph}-\mathrm{H}$ shows a hydrophobic and slightly polar properties due to the nature of its $\pi$-electron system that acts as a weak hydrogen bond acceptor. Many important chemicals are derived from $\mathrm{Ph}-\mathrm{H}$ by replacing one or more of its hydrogen atoms with another functional group. Fluorine is considered as isosteric with hydrogen (the van der Waals radius about 20\% larger than that of $\mathrm{H}$ ). According to this, when $\mathrm{C}-\mathrm{H}$ bond of the substrate is replaced with a $\mathrm{C}-\mathrm{F}$ bond it is expected not to exert a confounding steric influence (so called "mimic effect" of $\mathrm{F}$ for $\mathrm{H}$ ). Fluorobenzene like benzene is planar molecule. In view of the fact that fluorine is the most electronegative element, it is expected that groups containing fluorine have unique inductive effects on the physicochemical properties of the molecules bearing them. Fluorine can share three sets of lone-pair electrons with electron-deficient atoms intramolecularly or intermolecularly. Thus, when fluorine is incorporated into bioactive compounds, these substituents will influence strong effects on the binding affinity for the receptors or target enzymes, biological activities, and pharmacokinetics. Replacement of a specific $\mathrm{C}-\mathrm{H}$ bond with a $\mathrm{C}-\mathrm{F}$ bond can effectively block metabolic processes via hydroxylation of $\mathrm{C}-\mathrm{H}$ bonds, predominantly by the cytochrome P-450 family of enzymes (so called "block effect"). Due to incorporation of fluorine(s) into metabolism site(s) has been widely used to prevent deactivation of biologically active substances in vivo. It has recently been shown that polar $\mathrm{C}-\mathrm{F}$ bond-protein interactions play a critical role in the stabilization of fluorine - containing drugs and their target proteins. The majority of examples (include those between a $\mathrm{C}-\mathrm{F}$ bond and polar functional groups) from the protein crystallographic database indicate that a $\mathrm{C}-\mathrm{F}$ bond unit serves as a poor hydrogen-bond acceptor. It is also well known that incorporation of halogen groups increases the lipophilicity of organic compounds, especially aromatic compounds. Nevertheless, fluorobenzene $(\log \mathrm{P} \approx 2.27)$ is slightly more lipophilic than benzene $(\log \mathrm{P} \approx 2.13)$, but in contrast chlorobenzene is much more lipophilic $\log P=2.84$ ).

In the case of compound EP-40, the $\mathrm{Ph}-\mathrm{H}$ bond is replaced with the $\mathrm{Ph}-\mathrm{OH}$ bond. The introduction of hydroxy groups into the structure of a lead will normally produce analogues with an increased hydrophilic nature and low lipid solubility. It also provides a new center of hydrogen bonding, which could influence the binding of the analogue to its target site. $\mathrm{Ph}-\mathrm{OH}$ like $\mathrm{Ph}-\mathrm{H}$ and $\mathrm{Ph}-\mathrm{F}$ have planar geometry. Due to resonance stabilization $\mathrm{Ph}-\mathrm{OH}$ moiety is highly acidic, because it has a partial positive charge on the oxygen atom (three of the four contributing resonance structures possess a positive charge on the oxygen atom of the molecule). The effect of aromatic ring substituent on a receptor binding affinity of a parent structure could be interpreted in terms of the hydrogen binding donor and acceptor ability. The $\mathrm{Ph}-\mathrm{OH}$ hydroxyl group can act as hydrogen bond acceptor. Increase 
of hydrogen - bond accepting capability of the compound, effect the decrease in hydrophobicity and thus lipophilicity ( $\log \mathrm{P}$ of $\mathrm{Ph}-\mathrm{OH} \approx 1.51)$. All above facts suggests that hydrophobicity and hydrogen bond acceptor capacity of arylpiperazine moiety play significant role in the antiarrhythmic action. Additionally, in case of EP-40 it was experimentally proven that prolongation of Q-T interval, which suggests that the antiarrhythmic action can be related to class I/III. Consequently we assume that electrophysiologic profile of EP-40 is similar to RS87337 (Dumez et al. 1989).

Base on results presented above (both experimental and calculations) one can draw the hypothesis that compound EP40 possesses the affinity to cardiac $\mathrm{Na}^{+}$and $\mathrm{K}^{+}$channels (similar to class I/III antiarrhythmic agents). The limited scope of this study does not however allow us to confirm or deny the possibility that EP-40 may have ischaemia-selective actions on repolarization and refractoriness through actions on other systems, but this needs further research.

Acknowledgements This study was supported by the research grant from the UMK no. 29/2010.

Open Access This article is distributed under the terms of the Creative Commons Attribution Noncommercial License which permits any noncommercial use, distribution, and reproduction in any medium, provided the original author(s) and source are credited.

\section{References}

Becker OM, Marantz Y, Shacham S, Inbal B et al (2004) G proteincoupled receptors: in silico drug discovery in 3D. Proc Nat Acad Sci USA 101:11304-11309

Benfey BG, Elfellah MS, Ogilvie RI, Varma DR (1984) Antiarrhythmic effects of prazosin and propranolol during coronary artery occlusion and re-perfusion in $\operatorname{dogs}$ and pigs. $\mathrm{Br} \mathrm{J}$ Pharmacol 82:717-725

Bernauer M, Ernenputsch I (1988) Antagonistic effects of alphaadrenoceptor blocking agents on arrhythmias, enzyme release, and myocardial necrosis in isolated rat hearts with coronary occlusion and reperfusion. Naunyn-Schmiedeberg's Arch Pharmacol 338:88-95

Bernier M, Manning AS, Hearse DJ (1989) Ischemia-induced and reperfusion-induced arrhythmias: importance of heart rate. Am J Physiol 256:H1344-H1352

Bohm M, Diet F, Feiler G et al (1988) [alpha]-Adrenoceptors and [alpha]-Adrenoceptor-Mediated Positive Inotropic Effects in Failing Human Myocardium. J Cardiovasc Pharmacol 12:357

Boyett MR, Harrison SM, Janvier NC, McMorn SO, Owen JM, Shui $\mathrm{Z}$ (1996) A list of vertebrate cardiac ionic currents nomenclature, properties, function and cloned equivalents. Cardiovasc Res $32: 455-481$

Bralet J, Didier JP, Moreau D, Opie LH, Rochette L (1985) Effect of alpha-adrenoceptor antagonists (phentolamine, nicergoline and prazosin) on reperfusion arrhythmias and noradrenaline release in perfused rat heart. Br J Pharmac 84:009-018

Brodde OE, Bruck H, Leineweber K (2006) Cardiac adrenoceptors: physiological and pathophysiological relevance. J Pharm Sci 100:323-337
Brooks RR, Miller KE, Carpenter JF (1989) Broad sensitivity of rodent arrhythmia models to class I, II, III, and IV antiarrhythmic agents. Proc Soc Exp Biol Med 191:201-209

Carmeliet E (1999) Cardiac ionic currents and acute ischemia: from channels to arrhythmias. Physiol Rev 79:917-1017

Chiu G, Li S, Connolly PJ et al (2008) Phenylpiperazinyl) cyclohexylureas: discovery of $\alpha 1 \mathrm{a} / 1 \mathrm{~d}$-selective adrenergic receptor antagonists for the treatment of benign prostatic hyperplasia/lower urinary tract symptoms (BPH/LUTS). Bioorg Med Chem 18:640-644

Clerck F, Rong Lu H, Rossem K, Hermans A, Ammel K (2002) In vivo measurement of QT prolongation, dispersion and arrhythmogenesis: application to the preclinical cardiovascular safety pharmacology of a new chemical entity. Fundam Clin Pharmacol 16:125-140

Colucci WS (1982) Alpha-adrenergic receptor blockade with prazosin. Consideration of hypertension, heart failure, and potential new applications. Ann Inter Med 97:67-77

Corr PB, Witkowski F (1984) Arrhythmias associated with reperfusion: basic insights and clinical relevance. J Cardiovasc Pharmacol 6:S903

Corr PB, Penkoske PB, Sobel BE (1978) Adrenergic influences on arrhythmias due to coronary occlusion and reperfusion. Br Heart J 40(suppl):62-70

Corr PB, Shayman JA, Kramer JB, Kipnis RJ (1981) Increased alphaadrenergic receptors in ischemic cat myocardium: a potential mediator of electrophysiological derangements. J Clin Invest 67:1232-1236

Corr PB, Yamada KA, Witkowski FX (1986) Mechanisms controlling cardiac autonomic function and their relation to arrhythmogenesis. In: Fozzard HA, Jennings RB, Katz AM, Morgan HE (eds) The heart and cardiovascular system, scientific foundations. Raven Press, New York, pp 1343-1403

Crumb W, Cavero I (1999) QT interval prolongation by noncardiovascular drugs: issues and solutions for novel drug development. Pharm Sci Technolo Today 7:270-280

Curtis MJ, Macleod BA, Walker JA (1987) Models for the study of arrhythmias in myocardial ischaemia and infarction: the use of the rat. J Moll Cell Cardiol 19:399-419

Dumez D, Patmore L, Ferrandon P, Allely M, Armstrong JM (1989) Electrophysiologic, antiarrhythmic, and cardioprotective effects of $N$-[3, 5 dichlorophenyl] 4-[4-hydroxy-2-methoxy-phenyl] piperazine carboxamidine dihydrochloride (RS-87337). J Cardiovasc Pharmacol 14:184-193

Elmas E, Ahmad-Nejad P, Weiss C et al (2008) Plasminogen activator inhibitor-1 (PAI-1), toll-like receptor 4 (TLR4), factor II (FII), FXIII and fibrinogen polymorphisms are not associated with the prevalence of sudden death due to ventricular fibrillation during myocardial infarction. Clin Chem Lab Med 46:1329-1331

Estrada JC, Darbar D (2008) Clinical use of and future perspectives on antiarrhythmic drugs. Eur J Clin Pharmacol 64:1139-1146

Fleisher M, Belyakov S, Jansone D et al (2009) Investigation of the structure and prediction of the biological activity of 1, 3-bis (3-cyano6, 6-dimethyl-2-oxo-5, 6-dihydro-2H-pyran-4-yl)-2-(4-methoxyphenyl) propane. Chem Heterocycl Compd 45:531-535

Frisch MJ, Trucks GW, Schlegel HB et al (2004) Gaussian 03, revision D.01. Gaussian, Inc., Wallingford

GaussView, Version 4.1, Semichem, (2003) Inc., Shawnee Mission, KS

Gholivand K, Oroujzadeh N, Erben MF et al (2009) Synthesis, spectroscopy, computational study and prospective biological activity of two novel 1, 3, 2-diazaphospholidine-2, 4, 5-triones. Polyhedron 28:541-547

Golan DE, Tashjian AH, Armstrong EJ, Armstrong AW (2008) Principles of pharmacology: the pathophysiologic basis of drug therapy. Lippincott Williams \& Wilkins, London

Goldberger JJ, Cain ME, Hohnloser SH et al (2008) American Heart Association/American College of Cardiology Foundation/ Heart Rhythm Society Scientific Statement on noninvasive risk stratification techniques for identifying patients at risk for 
sudden cardiac death a scientific statement from the American Heart Association Council on Clinical Cardiology Committee on Electrocardiography and Arrhythmias and Council on Epidemiology and Prevention. J Am Coll Cardiol 52:11791199

Hayes ES, Pugsley MK, Goldin AL, Walker MJA (2002) Sodium channel blocking and antiarrhythmic actions of the novel arylpiperazine RSD992. Pharmacol Res 46:19-29

He Z, Huang L, Wu Y et al (2008) DDPH: improving cognitive deficits beyond its alpha 1-adrenoceptor antagonism in chronic cerebral hypoperfused rats. Eur J Pharmacol 88:178-188

Heusch G (1990) Alpha-adrenergic mechanisms in myocardial ischemia. Cir 81:1

Huikuri HV, Castellanos A, Myerburg RJ (2001) Sudden death due to cardiac arrhythmias. N Engl J Med 345:1473-1482

Ino T, Fishbein MC, Mandel W, Chen PS, Karaguezian H (1995) Cellular mechanisms of ventricular bipolar electrograms showing double and fractionated potentials. J Am Coll Cariol 26:10801089

Jain KS, Bariwal JB, Kathiravan MK et al (2008) Recent advances in selective $\alpha 1$-adrenoreceptor antagonists as antihypertensive agents. Bioorg Med Chem 16:4759-4800

Kromhout D (2007) Epidemiology of cardiovascular diseases in Europe. Public Health Nutr 4:441-457

Kulig K, Sapa J, Maciag D, Filipek B, Malawska B (2007) Synthesis and pharmacological evaluation of new 1-[3-(4-arylpiperazin-1yl)-2-hydroxypropyl]-pyrrolidin-2-one derivatives with antiarrhythmic, hypotensive, and alpha-adrenolytic activity. Arch Pharm Weinheim 340(9):466-475

Lamontagne D, Yamaguchi N, Nadeau R, Champlan J, Godin D, Campeau N (1986) Effects of sotalol, (-)-propranolol and prazosin on reperfusion-induced arrhythmias and increased cardiac norepinephrine release. Eur J Pharmacol 123:1-10

Landzberg JS, Parker JD, Gauthier DF et al (1991) Effects of myocardial alpha 1-adrenergic receptor stimulation and blockade on contractility in humans. Cir 84:1608

Langendorff O (1895) Untersuchungen am überlebenden Säugethierherzen. Pflügers Arch 61:291-332

Lubbe WF, Daries PS (1978) Ventricular arrhythmias associated with coronary artery occlusion and reperfusion in the isolated perfused rat heart: a model for assessment of antifibrillatory action of antiarrhythmic agents. Cardiovasc Res 12:212-220

Malawska B, Kulig K, Filipek B, Sapa J, Maciąg D, Zygmunt M, Antkiewicz-Michaluk L (2002) Synthesis, antiarrhythmic, and antihypertensive effects of novel 1-[2-hydroxy- or 1-[2-acetoxy3-arylalkylamino)-propyl]-pyrrolidin-2-one derivatives with adrenolytic activity. Eur J Med Chem 37(3):183-195

Malawska B, Kulig K, Gippert A, Filipek B, Sapa J, Maciąg D (2005) Design, synthesis and development of 1-subsituted pyrrolidin-2one derivatives as potential $\alpha_{1}$-adrenoceptor antagonist. Farmaco 60:793-803

Marwaha A, Goel RK, Mahajan MP (2007) PASS-predicted design, synthesis and biological evaluation of cyclic nitrones as nootropics. Bioorg Med Chem 17:5251-5255

Matyus P, Varro A, Papp JG, Wamhoff H, Varga I, Virag L (1997) Antiarrhythmic agents: current status and perspectives. Med Res Rev 17:427-451

Michelotti GA, Price DT, Schwinn DA (2000) alpha 1-adrenergic receptor regulation: basic science and clinical implications. Pharmacol Ther 88:281-309

Miyasaka Y, Barnes ME, Gersh BJ et al (2006) Secular trends in incidence of atrial fibrillation in Olmsted County, Minnesota, 1980 to 2000, and implications on the projections for future prevalence. Cir 114:119

Nattel S, Carlsson L (2006) Innovative approaches to anti-arrhythmic drug therapy. Nat Rev Drug Discov 5:1034-1050
Northover BJ (1983) A comparison of the electrophysiological actions of phentolamine with those of some other antiarrhythmic drugs on tissues isolated from the rat heart. Br J Pharmacol 80:85-93

Nowaczyk A, Kulig K, Malawska B (2009) 1-(3-(4-arylpiperazin-1yl)-propyl)- pyrrolidin-2-one derivatives as $\alpha 1$-adrenoceptor antagonists: a QSAR studies. QSAR Comb Sci 28:979-988

Nowaczyk A, Przybylski R, Kulig K, Malawska B (2010) Structure activity relationship studies of a number of $\alpha_{1}$-adrenoceptor antagonists and antiarrhythmic agents. Minf 29:343-351

Page C, Curtis M, Sutter M, Walker M, Hoffman B (2002) Integrated pharmacology. Mosby, Edinburgh, pp 361-376

PASS (Prediction of Biological Activity Spectra) 2010. Available at: http://www.ibmh.msk.su/PASS

Poroikov V, Filimonov D (eds) (2005) PASS: prediction of biological activity spectra for substances. Taylor \& Francis Group, LLC, Boca Raton

Poroikov V, Filimonov DA, Borodina YV et al (2000) Robustness of biological activity spectra predicting by computer program PASS for noncongeneric sets of chemical compounds. J Chem Inf Comput Sci 40:1349-1355

Rich MW (2009) Epidemiology of atrial fibrillation. J Interv Card Electrophysiol 25:3-8

Rohilla A, Rohilla S, Singh G et al (2010) Myocardial ischemic preconditioning: a novel approach to cardioprotection. J Pharm Res 3:132-140

Sharma A, Lee B, Saffitz B, Sobel B, Corr P (1983) Alpha adrenergic mediated accumulation of calcium in reperfused myocardium. $\mathrm{J}$ Clin Invest 72:802-818

Sheridan DJ, Penkoske PA, Sobel BE, Corr PB (1980) Alpha adrenergic contributions to dysrhythmia during myocardial ischemia and reperfusion in cats. J Clin Invest 65:161-171

Starmer CF, Laastra AA, Nesterenhs VW, Grant AO (1991) Proarrhythmic response to sodium channel blockade. Theor Model Numerical Experiments. Circulation 84:1364

Stewart JR, Burmeister WE, Burmeister J, Lucchesi BR (1980) Electrophysiologic and antiarrhythmic effects of phentolamine in experimental coronary artery occlusion and reperfusion in the dog. J Cardiovasc Pharmacol 2:77-91

Salvi S (2001) Protecting the myocardium from ischemic injury. A critical role for alpha1-adrenoreceptors? Chest 119: 1242-1249

Szekeres L, Papp JG (1975) Handbook of experimental pharmacology, vol XVI/3. Springer Verlag, New York

Thandroyen FT, Worthington MG, Higginson L, Opie LH (1983) The effect of alpha-adrenoceptor antagonist agents on reperfusion ventricular fibrillation and metabolic status in the isolated perfused rat heart. J Am Coll Cardiol 1:1056-1066

Thiyagarajan M (2002) alpha-adrenoceptor antagonists in the treatment of benign prostate hyperplasia. Pharmacol 65:119-128

Tolg R, Kurz T, Ungerer M, Schreieck J, Gorge B, Richard G (1997) Influence of alpha- and beta-adrenoceptor antagonists on ventricular fibrillation in ischemic rat hearts. NaunynSchmiedeberg's Arch Pharmacol 356:62-68

Uematsu T, Vozeh S, Ha HR, Hof RP, Follath F (1986) Coronary ligation-reperfusion arrhythmia models in anesthetized rats and isolated perfused rat hearts concentration-effect relationships of lidocaine. J Pharmacol Meth 16:53-61

Vaughan Williams EM (1975) Classification of antidysrhythmic drugs. Pharmacol Ther B1:115-138

Vaughan Williams EM (1981) Pharmacology of anti-arrhythmic agents. Pergamon, Oxford, pp 125-150

Walker MJA, Curtis MJ, Hearse DJ et al (1988) Cardiovasc Res 22:447-455

Yue T, Cheng HY, Lysko PG, Mckenna PJ, Feuerstein R, Gu JL, Lysko KA, Davis LL, Feuerstein G (1992) Carvedilol, a new vasodilator and beta adrenoceptor antagonist, is an antioxidant and free radical scavenger. J Pharmacol Exp Ther 263:1

Zhong H, Minneman KP (1999) A1-Adrenoceptor subtypes. Eur J Pharmacol 375:261-276 